\title{
Main Agronomic Traits and Photosynthetic Pathways of Potatoes
}

\author{
Peihua Li ${ }^{1}$, Qinglong $\operatorname{Tian}^{1}$, Zhengsong Peng ${ }^{1}$, Zhirong Fang ${ }^{1}$, Yuan Qing ${ }^{1}$, Huan Zhao ${ }^{2 *}$ \\ ${ }^{1}$ Xichang University, Xichang 615013, China \\ ${ }^{2}$ China West Normal University, Nanchong 637002, China
}

Corresponding Author Email: Zhaohuan_2010@163.com

https://doi.org/10.18280/ijdne.150317

Received: 5 January 2020

Accepted: 10 March 2020

\author{
Keywords: \\ potato, agronomic traits, physiological indices, \\ regression analysis, path analysis
}

\begin{abstract}
This paper attempts to disclose the effects of main agronomic traits and physiological indices on potato yield, under different agronomic measures. Four-factor five-level orthogonal test plan was designed by the strategy of quadratic orthogonal rotation combination (QORC). The test data were subjected to multiple regression analysis of variance (ANOVA), correlation analysis, and path analysis. The main results are as follows: Based on correlation, the main agronomic traits can be ranked as yield per plant> plant height $>$ stem diameter $>$ emergence rate $>$ number of tubers per plant $>$ leaf area index> number of main stems; the physiological indices can be ranked as net photosynthetic rate> intercellular carbon dioxide concentration> transpiration rate> chlorophyll content. Based on direct effect over potato yield, the main agronomic traits can be ranked as yield per plant $>$ leaf area index $>$ stem diameter $>$ plant height $>$ emergence rate> number of tubers per plant> number of main stems; the physiological indices can be ranked as net photosynthetic rate> intercellular carbon dioxide concentration $>$ chlorophyll content $>$ transpiration rate. Based on the direct contribution to the potato yield, the main agronomic traits can be ranked as yield per plant $>$ stem diameter> plant height $>$ leaf area index $>$ emergence rate> number of tubers per plant> number of main stems; the physiological indices can be ranked as net photosynthetic rate > intercellular carbon dioxide concentration > transpiration rate> chlorophyll content. To ramp up potato yield, priority should be given to enhance yield per plant and net photosynthetic rate. On the population, the plant height and stem diameter must match leaf area index in terms of planting density. Under high photosynthesis, the potato yield could be increased by reducing transpiration rate and intercellular carbon dioxide concentration.
\end{abstract}

\section{INTRODUCTION}

Most studies on potatoes focus on the dynamic changes of biological traits and tuber yield, failing to tackle the correlation between some traits and yield. In the aspect of physiology, some scholars have explored the photosynthesis of potatoes, and some have examined the physiological changes of tubers, but none have introduced biological traits into physiological research. To make up for these gaps, this paper systematically investigates the dynamic correlations between biological traits, photosynthetic physiology and yield of potatoes, and optimize the combination between plant traits and photosynthetic physiology, providing a scientific reference for the design of high yield techniques.

Our tests use the potato cultivar Qingshu 9, which features high yield, disease resistance, and good adaptability. The aim is to obtain realistic production data from different soil environments. The agronomic measures were designed by the strategy of quadratic orthogonal rotation combination (QORC). This design reduces the number of tests, eliminating the correlation between regression coefficients. The test site was representative in terms of space [1]. The tests lasted 2 years to prove the stability and reliability of the test data.

The growth state of potatoes is an objective measure of the yield variation induced by changes in agronomic measures and environmental conditions. Starting with the relationship of different agronomic traits, this paper explains the effects of changing agronomic traits on potato yield, and identifies the key factors affecting the high yield of potatoes, laying a theoretical basis for high-yield cultivation.

\section{METHODOLOGY}

\subsection{Test site}

The test site $\left(102^{\circ} 33^{\prime} \mathrm{E}, 27^{\circ} 22^{\prime} \mathrm{N}\right)$ is located in Cailuoluobo Village, Wudaoqing Town, Puge County, Liangshan Prefecture, southwestern China's Sichuan Province. The mean altitude of the test site is $2,080 \mathrm{~m}$.

The soil samples from the test site were analyzed at Soil and Fertilizer Research Institute, Sichuan Academy of Agricultural Sciences in 2018. The physical and chemical properties of the soil were summarized as: $\mathrm{pH} 6.5$, total nitrogen $(\mathrm{N}) 3.53 \mathrm{~g} / \mathrm{kg}$, total phosphorus $(\mathrm{P}) 1.93 \mathrm{~g} / \mathrm{kg}$, total potassium $(\mathrm{K}) 13.58 \mathrm{~g} / \mathrm{kg}$, alkali-hydrolyzable nitrogen $(\mathrm{N})$ $305 \mathrm{mg} / \mathrm{kg}$, and organic matter content $3.6 \%$. The soil has medium to high fertility.

According to the data from Puge County Meteorological Center, the annual mean temperature is $18^{\circ} \mathrm{C}$, the annual mean 
rainfall is $910 \mathrm{~mm}$, the rainy season lasts from June to August, and the frost-free period lasts 313 days.

\subsection{Materials and instruments}

The potato cultivar selected for our tests is Qingshu 9. The size of seed potatoes was controlled within $60-80 \mathrm{~g}$.

The fertilizers include urea $(46 \% \quad \mathrm{~N}$, Sinofert $)$, superphosphate $\left(16 \% \mathrm{P}_{2} \mathrm{O}_{5}\right.$, Yunnan Ruchun), and potassium sulfate $\left(52 \% \mathrm{~K}_{2} \mathrm{O}\right.$, Chuanhua Qingshang).
The instruments include electronic scale, table balance, non-contact chlorophyll meter, CIRAS-3 portable photosynthesis rate meter, and canopy meter.

\subsection{Test method}

The test plan was designed by four-factor QORC. As shown in Table 1, four factors were selected, namely, planting density $\left(\mathrm{X}_{1}\right), \mathrm{N}\left(\mathrm{X}_{2}\right), \mathrm{P}\left(\mathrm{X}_{3}\right)$, and $\mathrm{K}\left(\mathrm{X}_{4}\right)$. Each factor was divided into five levels.

Table 1. Factors and levels in the orthogonal test plan

\begin{tabular}{ccccccc}
\hline Factors & Intervals & \multicolumn{5}{c}{ Levels } \\
& & -2 & -1 & 0 & 1 & 2 \\
\hline Planting density $\left(\mathrm{X}_{1}\right) /\left(\right.$ dibble $\left./ 667 \mathrm{~m}^{2}\right)$ & 500 & 3500 & 4000 & 4500 & 5000 & 5500 \\
$\mathrm{~N}\left(\right.$ urea $\left.\mathrm{X}_{2}\right) /\left(\mathrm{kg} / 667 \mathrm{~m}^{2}\right)$ & 5 & 5 & 10 & 15 & 20 & 25 \\
$\mathrm{P}\left(\right.$ monopotassium phosphate $\left.\mathrm{X}_{3}\right) /\left(\mathrm{kg} / 667 \mathrm{~m}^{2}\right)$ & 10 & 10 & 20 & 30 & 40 & 50 \\
$\mathrm{~K}$ (potassium sulfate $\left.\mathrm{X}_{4}\right) /\left(\mathrm{kg} / 667 \mathrm{~m}^{2}\right)$ & 15 & 20 & 35 & 50 & 65 & 80 \\
\hline
\end{tabular}

Table 2. QORC-based combinations

\begin{tabular}{ccccc}
\hline Plot & \multicolumn{3}{c}{ Level } & \\
& Planting density $\left(\mathrm{X}_{1}\right)$ & $\mathrm{N}\left(\mathrm{X}_{2}\right)$ & $\mathrm{P}\left(\mathrm{X}_{3}\right)$ & $\mathrm{K}\left(\mathrm{X}_{4}\right)$ \\
\hline 1 & 1 & 1 & 1 & 1 \\
2 & 1 & 1 & 1 & -1 \\
3 & 1 & 1 & -1 & 1 \\
4 & 1 & 1 & -1 & -1 \\
5 & 1 & -1 & 1 & 1 \\
6 & 1 & -1 & 1 & -1 \\
7 & 1 & -1 & -1 & 1 \\
8 & 1 & -1 & -1 & -1 \\
9 & -1 & 1 & 1 & 1 \\
10 & -1 & 1 & 1 & -1 \\
11 & -1 & 1 & -1 & 1 \\
12 & -1 & 1 & -1 & -1 \\
13 & -1 & -1 & 1 & 1 \\
14 & -1 & -1 & 1 & -1 \\
15 & -1 & -1 & -1 & 1 \\
16 & -1 & -1 & -1 & -1 \\
17 & -2 & 0 & 0 & 0 \\
18 & 2 & 0 & 0 & 0 \\
19 & 0 & -2 & 0 & 0 \\
20 & 0 & 2 & 0 & 0 \\
21 & 0 & 0 & -2 & 0 \\
22 & 0 & 0 & 2 & 0 \\
23 & 0 & 0 & 0 & -2 \\
24 & 0 & 0 & 0 & 2 \\
25 & 0 & 0 & 0 & 0 \\
26 & 0 & 0 & 0 & 0 \\
27 & 0 & 0 & 0 & 0 \\
28 & 0 & 0 & 0 & 0 \\
29 & 0 & 0 & 0 & 0 \\
30 & 0 & 0 & 0 & 0 \\
31 & 0 & 0 & 0 & 0 \\
32 & 0 & 0 & 0 & 0 \\
33 & 0 & 0 & 0 & 0 \\
34 & 0 & 0 & 0 & 0 \\
35 & 0 & 0 & 0 & 0 \\
36 & 0 & 0 & 0 & 0 \\
\hline & & & & \\
& 0 & 1 & 0 & 0
\end{tabular}

As shown in Table 2, a total of 36 plots were designed in the $712.53 \mathrm{~m}^{2}$ test site. Each plot is $13.33 \mathrm{~m}^{2}$ in size (length: $5.34 \mathrm{~m}$; width: $2.5 \mathrm{~m}$ ). There is a $0.5 \mathrm{~m}$-wide walkway between every two plots. A normal protection belt $\left(55.04 \mathrm{~m}^{2}\right)$ was arranged outside the plots.

On March 8, 2018, the seed potatoes were sown in two rows at a spacing of $0.83 \mathrm{~cm}$ with a $25 \mathrm{~cm}$ height ridge, using a dibbler.

During the six days before and after the flowering period, 10 plants were selected from each plot for field measurement during the six days before and after the flowering period: plant height $\left(\mathrm{X}_{1}\right)$ and stem diameter $\left(\mathrm{X}_{3}\right)$ were obtained with a tape measure; the number of main stems $\left(\mathrm{X}_{2}\right)$ and emergence rate $\left(\mathrm{X}_{6}\right)$ were counted; leaf area index $\left(\mathrm{X}_{7}\right)$ was measured by canopy meter; transpiration rate $\left(\mathrm{X}_{8}\right)$, net photosynthetic rate $\left(X_{9}\right)$, intercellular carbon dioxide concentration $\left(X_{10}\right)$ and chlorophyll content $\left(\mathrm{X}_{11}\right)$ were measured by IRAS-3 portable photosynthesis rate meter.

On August 25, 2018, the potatoes were harvested, and subjected to measurement of yield per plant $\left(\mathrm{X}_{5}\right)$, plot yield $(\mathrm{y})$, and number of tubers per plant $\left(\mathrm{X}_{4}\right)$.

The test data were analyzed on DPS 9.01 software.

\section{RESULTS AND ANALYSIS}

\subsection{Multiple regression analysis of variance (ANOVA) for potato yield and main agronomic traits}

\subsubsection{Multiple regression ANOVA}

Based on the results on the main agronomic traits and yield of potatoes (Table 3), a multiple regression ANOVA table was prepared (Table 4). The main agronomic traits had highly significant regression relationship $\left(F=5.0342>F_{0.01(7,28)}=3.36\right)$ with potato yield, indicating that the multiple regression equation holds.

\subsubsection{Optimal regression equation}

With the aid of DPS, the data in Table 3 were subjected to multiple stepwise regression analysis. The insignificant agronomic traits were thus removed. Through the stepwise regression, the optimal regression equation can be obtained as:

$$
Y=747.62018-619.2426 \mathrm{X}_{3}+1770.2371 \mathrm{X}_{5}+310.1323 \mathrm{X}_{7}
$$

where, $Y$ is potato yield $\left(\mathrm{kg} / 667 \mathrm{~m}^{2}\right) ; \mathrm{X}_{3}$ is stem diameter $(\mathrm{cm})$; $\mathrm{X}_{5}$ is yield per plant $(\mathrm{kg}) ; \mathrm{X}_{7}$ is leaf area index.

The above regression equation shows that potato yield has significant regression relationship with stem diameter $(\mathrm{cm})$, yield per plant $(\mathrm{kg})$, and leaf area index, but no significant regression relationship with plant height, number of main stems, number of tubers per plant, or emergence rate. 
If other factors are fixed, the mean potato yield reduced by $61.9 \mathrm{~kg}$ for every $0.1 \mathrm{~cm}$ increase in stem diameter, grew by
$177 \mathrm{~kg}$ for every $100 \mathrm{~g}$ increase in yield per plant, and grew by $31 \mathrm{~kg}$ for every 0.1 increase in leaf area index.

Table 3. Main agronomic traits and yield of potatoes

\begin{tabular}{|c|c|c|c|c|c|c|c|c|}
\hline Combination & $\begin{array}{c}\text { Plant } \\
\text { height } \\
\mathrm{cm}\end{array}$ & $\begin{array}{l}\text { Number of } \\
\text { main stems }\end{array}$ & $\begin{array}{c}\text { Stem } \\
\text { diameter } \\
\mathrm{cm}\end{array}$ & $\begin{array}{c}\text { Number of } \\
\text { tubers per plant }\end{array}$ & $\begin{array}{c}\text { Yield per } \\
\text { plant }\end{array}$ & $\begin{array}{c}\text { Emergence } \\
\text { rate }\end{array}$ & $\begin{array}{c}\text { Leaf area } \\
\text { index }\end{array}$ & $\begin{array}{c}\text { Yield } \\
\mathrm{kg} / 667 \mathrm{~m}^{2}\end{array}$ \\
\hline 1 & 115.0 & 3.2 & 1.38 & 4.6 & 0.424 & 0.71 & 3.2 & $1,520.0$ \\
\hline 2 & 119.6 & 3.0 & 1.68 & 4.8 & 0.438 & 0.68 & 3.1 & $1,720.0$ \\
\hline 3 & 122.4 & 2.2 & 1.26 & 4.9 & 0.436 & 0.75 & 2.9 & $1,832.5$ \\
\hline 4 & 118.4 & 3.8 & 1.06 & 4.5 & 0.433 & 0.66 & 3.3 & $1,695.0$ \\
\hline 5 & 112.0 & 2.6 & 1.18 & 4.5 & 0.508 & 0.77 & 2.7 & $1,692.5$ \\
\hline 6 & 104.0 & 2.2 & 1.10 & 8 & 0.646 & 0.75 & 3.2 & $2,102.5$ \\
\hline 7 & 114.8 & 3.2 & 1.36 & 5.1 & 0.406 & 0.75 & 3.3 & $1,740.0$ \\
\hline 8 & 106.6 & 3.0 & 1.10 & 5.3 & 0.493 & 0.72 & 2.9 & $1,772.5$ \\
\hline 9 & 135.2 & 2.4 & 1.58 & 5.1 & 0.536 & 0.74 & 3.1 & $1,360.0$ \\
\hline 10 & 126.6 & 2.6 & 1.36 & 4.8 & 0.461 & 0.81 & 3.0 & $1,452.5$ \\
\hline 11 & 124.4 & 3.4 & 1.48 & 5.2 & 0.455 & 0.79 & 3.0 & $1,492.5$ \\
\hline 12 & 127.4 & 4.8 & 1.38 & 5.5 & 0.520 & 0.81 & 2.8 & $1,410.0$ \\
\hline 13 & 115.6 & 2.8 & 1.20 & 5.6 & 0.444 & 0.86 & 3.3 & $1,572.5$ \\
\hline 14 & 113.4 & 3.0 & 1.46 & 5.7 & 0.501 & 0.89 & 3.5 & $1,852.5$ \\
\hline 15 & 120.8 & 2.8 & 1.42 & 5.2 & 0.498 & 0.83 & 3.2 & $1,807.5$ \\
\hline 16 & 115.2 & 3.2 & 1.28 & 4.9 & 0.520 & 0.94 & 2.9 & $1,812.5$ \\
\hline 17 & 119.4 & 3.2 & 1.22 & 4.8 & 0.499 & 0.96 & 2.5 & $1,580.0$ \\
\hline 18 & 116.6 & 3.6 & 1.32 & 5.4 & 0.448 & 0.73 & 3.2 & $1,632.5$ \\
\hline 19 & 109.4 & 3.0 & 1.36 & 5.5 & 0.492 & 0.80 & 3.2 & $1,667.5$ \\
\hline 20 & 115.6 & 4.0 & 1.24 & 4.6 & 0.438 & 0.78 & 2.6 & $1,625.0$ \\
\hline 21 & 116.8 & 3.0 & 1.32 & 5.7 & 0.548 & 0.76 & 2.7 & $1,877.5$ \\
\hline 22 & 122.8 & 3.2 & 1.28 & 5.9 & 0.501 & 0.73 & 3.1 & $1,715.0$ \\
\hline 23 & 128.4 & 4.2 & 1.24 & 5.7 & 0.516 & 0.80 & 2.8 & $2,035.0$ \\
\hline 24 & 121.0 & 3.6 & 1.18 & 5.1 & 0.441 & 0.77 & 3.0 & $1,805.0$ \\
\hline 25 & 116.4 & 3.6 & 1.12 & 5.4 & 0.554 & 0.89 & 3.2 & $2,117.5$ \\
\hline 26 & 114.8 & 3.2 & 1.38 & 5.6 & 0.557 & 0.67 & 2.9 & $1,660.0$ \\
\hline 27 & 117.0 & 3.2 & 1.16 & 5.3 & 0.518 & 0.84 & 3.2 & $2,017.5$ \\
\hline 28 & 111.4 & 3.4 & 1.20 & 5.3 & 0.599 & 0.86 & 3.1 & $1,947.5$ \\
\hline 29 & 117.6 & 3.3 & 1.32 & 5.5 & 0.546 & 0.82 & 3.2 & $1,980.0$ \\
\hline 30 & 118.8 & 3.8 & 1.22 & 5.5 & 0.581 & 0.81 & 3.0 & $2,000.0$ \\
\hline 31 & 106.2 & 5.2 & 1.20 & 6.4 & 0.624 & 0.80 & 2.9 & $1,972.5$ \\
\hline 32 & 106.4 & 4.4 & 1.32 & 6.6 & 0.513 & 0.78 & 3.1 & $1,930.0$ \\
\hline 33 & 110.4 & 3.2 & 1.30 & 5.1 & 0.567 & 0.91 & 2.8 & $1,962.5$ \\
\hline 34 & 118.8 & 3.3 & 1.24 & 6.2 & 0.551 & 0.82 & 3.2 & $2,002.5$ \\
\hline 35 & 107.4 & 3.8 & 1.28 & 4.5 & 0.545 & 0.91 & 3.3 & $2,347.5$ \\
\hline 36 & 107.2 & 3.0 & 1.48 & 6.5 & 0.642 & 0.74 & 2.8 & $1,747.5$ \\
\hline
\end{tabular}

Table 4. Multiple regression ANOVA table for main agronomic traits and yield of potatoes

\begin{tabular}{cccccc}
\hline Source & Sum of squares & df & Mean square & F-statistic & p-value \\
\hline Regression & $940,808.9536$ & 7 & $134,401.2791$ & 5.0342 & 0.0009 \\
Residual & $747,538.7894$ & 28 & $26,697.8139$ & & \\
Total & $1,688,347.743$ & 35 & $48,238.5069$ & & \\
\hline
\end{tabular}

\subsection{Multiple regression ANOVA for potato yield and physiological indices}

\subsubsection{Multiple regression ANOVA}

Based on the results on the physiological indices and yield of potatoes (Table 5), a multiple regression ANOVA table was prepared (Table 6). The physiological indices had highly significant regression relationship $\left(F=33.4747>F_{0.01(7,28)}=3.36\right)$ with potato yield, indicating that the multiple regression equation holds.

\subsubsection{Optimal regression equation}

With the aid of DPS, the data in Table 5 were subjected to multiple stepwise regression analysis. The insignificant agronomic traits were thus removed. Through the stepwise regression, the optimal regression equation can be obtained as:

$$
\mathrm{Y}=305.7415+112.2574 \mathrm{X}_{9}-1.1569 \mathrm{X}_{10}
$$

where, $\mathrm{Y}$ is potato yield $\left(\mathrm{kg} / 667 \mathrm{~m}^{2}\right) ; \mathrm{X}_{9}$ is net photosynthetic rate $\left(\mu \mathrm{molCO} 2 / \mathrm{m}^{2} \mathrm{~s}\right) ; \mathrm{X}_{10}$ is intercellular carbon dioxide concentration $(\mu \mathrm{mol} / \mathrm{mol})$.

The above regression equation shows that potato yield has significant regression relationship with net photosynthetic rate $\left(\mu \mathrm{molCO} 2 / \mathrm{m}^{2} \mathrm{~s}\right)$ and intercellular carbon dioxide concentration $(\mu \mathrm{mol} / \mathrm{mol})$, but no significant regression relationship with transpiration rate or chlorophyll content.

If other factors are fixed, the mean potato yield grew by $112.3 \mathrm{~kg}$ for every $1 \mu \mathrm{molCO}_{2} / \mathrm{m}^{2} \mathrm{~s}$ increase in net photosynthetic rate, and dropped by $11.6 \mathrm{~kg}$ for every $10 \mu \mathrm{mol} / \mathrm{mol}$ increase in intercellular carbon dioxide concentration. 
Table 5. Physiological indices and yield of potatoes

\begin{tabular}{|c|c|c|c|c|c|}
\hline Combinations & $\begin{array}{c}\text { Transpiration } \\
\text { rate } \\
\mathrm{mmolH} \mathrm{H}_{2} \mathrm{O} / \mathrm{m}^{2} \mathrm{~s} \\
\end{array}$ & $\begin{array}{c}\text { Net photosynthetic } \\
\text { rate } \\
\mu \mathrm{molCO} / \mathrm{m}^{2} \mathrm{~s} \\
\end{array}$ & $\begin{array}{c}\text { Intercellular carbon } \\
\text { dioxide concentration } \\
\mu \mathrm{mol} / \mathrm{mol}\end{array}$ & $\begin{array}{c}\text { Chlorophyll } \\
\text { content } \\
\mathrm{mg} / \mathrm{g} \\
\end{array}$ & $\begin{array}{c}\text { Yield } \\
\mathrm{kg} / 667 \mathrm{~m}^{2} \\
\end{array}$ \\
\hline 1 & 4.595 & 15.20 & 397.0 & 47.0 & $1,520.0$ \\
\hline 2 & 5.515 & 17.40 & 396.0 & 45.3 & $1,720.0$ \\
\hline 3 & 5.730 & 17.60 & 396.5 & 40.4 & $1,832.5$ \\
\hline 4 & 5.215 & 16.60 & 393.0 & 48.0 & $1,695.0$ \\
\hline 5 & 5.470 & 15.65 & 390.0 & 47.0 & $1,692.5$ \\
\hline 6 & 5.325 & 18.50 & 385.5 & 43.6 & $2,102.5$ \\
\hline 7 & 5.445 & 17.60 & 383.0 & 45.3 & $1,740.0$ \\
\hline 8 & 4.860 & 16.95 & 396.5 & 41.0 & $1,772.5$ \\
\hline 9 & 3.165 & 13.50 & 401.5 & 41.9 & $1,360.0$ \\
\hline 10 & 4.460 & 15.35 & 398.0 & 40.4 & $1,452.5$ \\
\hline 11 & 4.345 & 15.85 & 391.5 & 36.2 & $1,492.5$ \\
\hline 12 & 3.635 & 14.25 & 357.5 & 42.5 & $1,410.0$ \\
\hline 13 & 4.845 & 15.10 & 347.0 & 40.5 & $1,572.5$ \\
\hline 14 & 5.595 & 17.10 & 369.5 & 35.3 & $1,852.5$ \\
\hline 15 & 5.295 & 16.30 & 355.5 & 42.6 & $1,807.5$ \\
\hline 16 & 5.360 & 17.30 & 398.5 & 45.6 & $1,812.5$ \\
\hline 17 & 5.445 & 16.70 & 374.5 & 44.0 & $1,580.0$ \\
\hline 18 & 4.120 & 14.95 & 341.5 & 40.2 & $1,632.5$ \\
\hline 19 & 4.695 & 16.70 & 334.0 & 39.5 & $1,667.5$ \\
\hline 20 & 5.980 & 14.80 & 377.0 & 43.6 & $1,625.0$ \\
\hline 21 & 4.625 & 16.95 & 359.5 & 39.1 & $1,877.5$ \\
\hline 22 & 5.360 & 15.75 & 419.0 & 41.1 & $1,715.0$ \\
\hline 23 & 6.470 & 18.80 & 391.0 & 41.2 & $2,035.0$ \\
\hline 24 & 5.810 & 19.40 & 403.0 & 43.4 & $1,805.0$ \\
\hline 25 & 4.060 & 19.40 & 371.0 & 42.0 & $2,117.5$ \\
\hline 26 & 2.392 & 15.00 & 383.0 & 42.9 & $1,660.0$ \\
\hline 27 & 3.400 & 18.10 & 302.0 & 42.6 & $2,017.5$ \\
\hline 28 & 3.292 & 17.00 & 259.0 & 43.9 & $1,947.5$ \\
\hline 29 & 3.340 & 18.90 & 292.0 & 43.2 & $1,980.0$ \\
\hline 30 & 3.600 & 18.60 & 332.0 & 39.8 & $2,000.0$ \\
\hline 31 & 3.230 & 18.10 & 305.0 & 43.8 & $1,972.5$ \\
\hline 32 & 2.792 & 17.50 & 262.0 & 40.7 & $1,930.0$ \\
\hline 33 & 3.260 & 18.30 & 314.0 & 43.6 & $1,962.5$ \\
\hline 34 & 4.060 & 18.90 & 318.0 & 42.9 & $2,002.5$ \\
\hline 35 & 4.400 & 19.50 & 317.0 & 42.1 & $2,347.5$ \\
\hline 36 & 2.350 & 16.00 & 338.0 & 39.5 & $1,747.5$ \\
\hline
\end{tabular}

Table 6. Multiple regression ANOVA table for physiological indices and yield of potatoes

\begin{tabular}{cccccc}
\hline Source & Sum of squares & df & Mean square & F-statistic & p-value \\
\hline Regression & $1,370,948.728$ & 4 & $342,737.1819$ & 33.4747 & 0.0001 \\
Residual & $317,399.0154$ & 31 & $10,238.6779$ & & \\
Total & $1,688,347.743$ & 35 & $48,238.5069$ & & \\
\hline
\end{tabular}

\subsection{Correlation analysis}

3.3.1 Correlations between main agronomic traits and potato yield

As shown in Table 7, potato yield is positively correlated with number of main stems, number of tubers per plant, yield per plant, emergence rate, and leaf area index, and negatively with plant height and stem diameter.

Thick stem is conducive to material transportation and yield formation, too thin stem plant is easy to lodging; potato plant is too large, waste carbohydrate, and aggravate the degree of field closure, plant is too small, the light energy utilization rate is reduced, is not conducive to the formation of yield, indicating that plant height and stem diameter have a certain range of limitations [2].

The number of tubers per plant and yield per plant had significant positive effect, and both had positive correlation with potato yield, but only the yield per plant reached extremely significant, which indicated that increasing the yield per plant could increase the yield of potato [3]. Plant height and stem diameter had significant positive effect, and plant height had significant negative effect on tuber number per plant and yield per plant, which indicated that plant height and stem diameter were closely related to potato growth process and had negative effect on yield, and too high plant height was not conducive to the number of tubers per plant and yield per plant. Therefore, plant height and stem diameter should be controlled in the process of planting to achieve the effect of increasing potato yield

Plant height has a significant positive correlation with stem diameter, but significant negative correlations with number of tubers per plant and yield per plant. It can be seen that plant height and stem diameter are closely related during potato growth, and both factors suppress potato yield; an excessively high plant height is not conducive to number of tubers per plant and yield per plant. Therefore, both plant height and stem diameter should be controlled to boost potato yield. 
Table 7. Correlations between main agronomic traits and potato yield

\begin{tabular}{|c|c|c|c|c|c|c|c|c|}
\hline Agronomic traits & $\mathbf{X}_{1}$ & $\mathbf{X}_{2}$ & $\mathbf{X}_{3}$ & $\mathbf{X}_{4}$ & $\mathbf{X}_{5}$ & $X_{6}$ & $\mathbf{X}_{7}$ & $\mathbf{y}$ \\
\hline $\mathrm{X}_{1}$ & 1 & & & & & & & \\
\hline $\mathrm{X}_{2}$ & -0.0769 & 1 & & & & & & \\
\hline $\mathrm{X}_{3}$ & $0.3325^{*}$ & -0.1701 & 1 & & & & & \\
\hline $\mathrm{X}_{4}$ & $-0.3612 *$ & 0.0612 & -0.1078 & 1 & & & & \\
\hline $\mathrm{X}_{5}$ & $-0.3815^{*}$ & 0.111 & -0.1429 & $0.632 * *$ & 1 & & & \\
\hline $\mathrm{X}_{6}$ & -0.0859 & 0.0949 & -0.1765 & -0.0903 & 0.2422 & 1 & & \\
\hline $\mathrm{X}_{7}$ & -0.0971 & -0.1406 & 0.0722 & 0.1262 & -0.1504 & -0.051 & 1 & \\
\hline $\mathrm{y}$ & $-0.489 * *$ & 0.1757 & $-0.4279 *$ & 0.3228 & $0.5074 * *$ & $0.3358 *$ & 0.2157 & 1 \\
\hline
\end{tabular}

Note: * means when $\mathrm{a}=0.05, \mathrm{r}=0.3291$ and $\mathrm{p}<0.05$ (significant level); ** means when $\mathrm{a}=0.01, \mathrm{r}=0.4238$ and $\mathrm{p}<0.01$ (highly significant level).

3.3.2 Correlations between physiological indices and potato yield

Table 8. Correlations between physiological indices and potato yield

\begin{tabular}{cccccc}
\hline $\begin{array}{c}\text { Physiological } \\
\text { indices }\end{array}$ & $\mathbf{X}_{\mathbf{8}}$ & $\mathbf{X}_{\mathbf{9}}$ & $\mathbf{X}_{\mathbf{1 0}}$ & $\mathbf{X}_{\mathbf{1 1}}$ & $\mathbf{y}$ \\
\hline $\mathrm{X}_{8}$ & 1 & & & & \\
$\mathrm{X}_{9}$ & 0.0985 & 1 & & & \\
$\mathrm{X}_{10}$ & $0.6212^{* *}$ & -0.3192 & 1 & & \\
$\mathrm{X}_{11}$ & 0.1335 & 0.0491 & 0.1002 & 1 & \\
$\mathrm{y}$ & -0.0522 & $0.8767^{* *}$ & $\begin{array}{c}- \\
0.4768^{* *}\end{array}$ & 0.0078 & 1 \\
\hline
\end{tabular}

Note: * means when $\mathrm{a}=0.05, \mathrm{r}=0.3291$ and $\mathrm{p}<0.05$ (significant level); ** means when $\mathrm{a}=0.01, \mathrm{r}=0.4238$ and $\mathrm{p}<0.01$ (highly significant level).

As shown in Table 8, potato yield is positively correlated with net photosynthetic rate, and chlorophyll content, but negatively correlated with transpiration rate, and intercellular carbon dioxide concentration.

The $\mathrm{R}$ between transpiration rate and intercellular carbon dioxide concentration was 0.6212 , indicating that the two factors have highly significant positive correlation. Besides, both factors have negative effects on potato yield.

The $\mathrm{R}$ between potato yield and intercellular carbon dioxide concentration was -0.4768 , a sign of highly significant negative correlation between the two factors. Hence, intercellular carbon dioxide concentration suppresses potato yield.

By contrast, net photosynthetic rate has a highly significant positive correlation with potato yield, indicating that this factor is the key promoter of potato yield.

\subsection{Path analysis}

3.4.1 Path analysis between main agronomic traits and potato yield

As shown in Table 9, the main agronomic traits can be ranked as yield per plant, leaf area index, stem diameter, plant height, emergence rate, number of tubers per plant, number of main stems in descending order of direct effect on potato yield, and as number of tubers per plant, plant height, emergence rate, stem diameter, leaf area index, number of main stems, yield per plant in descending order of indirect effect on potato yield.

(1) Effect of yield per plant $\left(\mathrm{X}_{5}\right)$ on potato yield

The direct path coefficient between yield per plant and potato yield was 0.449 . Among the seven agronomic traits, yield per plant has the greatest direct impact on potato yield, and plays an important role in ramping up potato yield. In terms of indirect effect, yield per plant exerts a positive impact on plant height, number of main stems, stem diameter, and emergence rate, and a negative impact on number of tubers per plant, and leaf area index. The overall indirect effect is positive but insignificant. Therefore, yield per plant is a key factor that directly affects potato yield.

(2) Effect of leaf area index $\left(X_{7}\right)$ on potato yield

The direct path coefficient between leaf area index and potato yield was 0.318 , i.e. this factor has a significant positive effect on potato yield. Within a certain range of planting density, leaf area index can effectively promote potato yield. In terms of indirect effect, leaf area index exerts a positive impact on plant height, and a negative impact on all the other five traits, especially on yield per plant. The overall indirect effect is slight negative. Therefore, an excessively high leaf area index hinders the promoting effects of other traits on yield. The plant profile must be adjusted to increase the potato yield.

(3) Effect of stem diameter $\left(\mathrm{X}_{3}\right)$ on potato yield

The direct path coefficient between stem diameter and potato yield was -0.284 , i.e. this factor has a significant negative effect on potato yield. If the stem is too thick, it is difficult to increase potato yield. In terms of indirect effect, stem diameter exerts a positive impact on number of tubers per plant, and leaf area index, and a negative impact on plant height, and yield per plant. The overall indirect effect is negative, indicating that stem diameter suppresses potato yield.

(4) Effect of plant height $\left(X_{1}\right)$ on potato yield

The direct path coefficient between plant height and potato yield was -0.207 , i.e. this factor has a negative effect on potato yield. In terms of indirect effect, plant height exerts a positive impact on number of tubers per plant, and a significant negative impact on stem diameter. The overall indirect effect is negative, revealing that the yield is suppressed by the interaction between plant height and stem diameter.

(5) Effect of emergence rate $\left(X_{6}\right)$ on potato yield

The direct path coefficient between emergence rate and potato yield was 0.157 , i.e. this factor has a positive effect on potato yield. In terms of indirect effect, leaf area index exerts a positive impact on yield per plant and stem diameter. The overall indirect effect is positive, and greater than the direct effect. Hence, emergence rate mainly has an indirect effect on potato yield.

(6) Effect of number of tubers per plant $\left(\mathrm{X}_{4}\right)$ on potato yield

The direct path coefficient between number of tubers per plant and potato yield was -0.098 , i.e. this factor has a small negative effect on potato yield. In terms of indirect effect, number of tubers per plants exerts a positive impact on yield per plant. The number of tubers per plant has greater impact on yield per plant than on any other trait. The overall indirect effect is highly positive, indicating that number of tubers per plant affects potato yield indirectly via its effect on yield per plant.

(7) Effect of number of main stems $\left(\mathrm{X}_{2}\right)$ on potato yield

The direct and indirect path coefficients between number of main stems and potato yield were 0.097 and 0.078, 
respectively. This factor slightly affects potato yield via its effect on stem diameter and yield per plant.

(8) Degree of determination

By absolute value, the 29 coefficients of determination can be ranked in descending order as dy.e $>$ dy $.5>$ dy $.7>$ dy $.3>$ dy $.15>$ dy $.45>$ dy $.57>$ dy $.1>$ dy $.13>$ dy .3 $5>$ dy $.56>$ dy $.6>$ dy $.36>$ dy $.14>$ dy $.37>$ dy $.17>$ dy $.25>$ dy $.4>$ dy .2 $>$ dy $.23>$ dy $.27>$ dy $.47>$ dy $.34>$ dy $.16>$ dy $.67>$ dy. $12>$ dy $.26>$ dy. $46>$ dy.24. From the ranking of these coefficients, it is clear that environmental error has the greatest effect on potato yield, followed in turn by the mutual effect between yield per plant and leaf area index, stem diameter, plant height and yield per plant, and yield per plant and leaf area index.

(9) Contributions of agronomic traits to the reliability $\mathrm{R}^{2}$ of regression equation

The contributions of independent variables were $P_{y .1} r_{1 y}=0.1012, P_{y .2} r_{2 y}=0.0171, P_{y .3} r_{3 y}=0.1216, P_{y .4} r_{4 y}=-0.0304$, $P_{y .5} r_{5 y}=0.2276, P_{y .6} r_{6 y}=0.0528$, and $P_{y .7} r_{7 y}=0.0685$. By the contribution to the reliability $\mathrm{R}^{2}$, the agronomic traits can be ranked in descending order as yield per plant $\left(\mathrm{X}_{5}\right)$, stem diameter $\left(X_{3}\right)$, plant height $\left(X_{1}\right)$, leaf area index $\left(X_{7}\right)$, emergence rate $\left(\mathrm{X}_{6}\right)$, number of tubers per plant $\left(\mathrm{X}_{4}\right)$, number of main stems $\left(\mathrm{X}_{2}\right)$.

Table 9. Pathways between main agronomic traits and potato yield

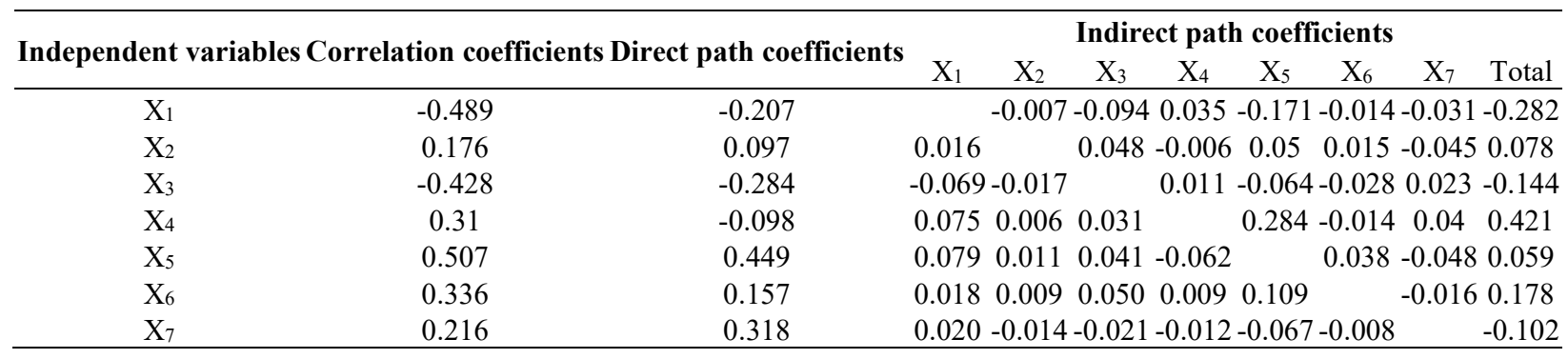

Table 10. Pathways between physiological indices and potato yield

\begin{tabular}{|c|c|c|c|c|c|c|c|}
\hline \multirow{2}{*}{ Independent variables } & \multirow{2}{*}{ Correlation coefficients } & \multirow{2}{*}{ Direct path coefficients } & \multicolumn{5}{|c|}{ Indirect path coefficients } \\
\hline & & & $\mathrm{X}_{8}$ & $\mathrm{X}_{9}$ & $\mathrm{X}_{10}$ & $\mathrm{X}_{11}$ & Total \\
\hline $\mathrm{X}_{8}$ & -0.052 & 0.010 & & 0.079 & -0.140 & -0.001 & -0.062 \\
\hline $\mathrm{X}_{9}$ & 0.877 & 0.804 & 0.001 & & 0.072 & -0.001 & 0.072 \\
\hline $\mathrm{X}_{10}$ & -0.477 & -0.225 & 0.006 & -0.257 & & -0.001 & -0.252 \\
\hline $\mathrm{X}_{11}$ & 0.008 & -0.011 & 0.001 & 0.039 & -0.023 & & 0.018 \\
\hline
\end{tabular}

3.4.2 Path analysis between physiological indices and potato yield

As shown in Table 10, the main physiological indices can be ranked as net photosynthetic rate, intercellular carbon dioxide concentration, chlorophyll content, transpiration rate in descending order of direct effect on potato yield, and as intercellular carbon dioxide concentration, chlorophyll content, transpiration rate, net photosynthetic rate in descending order of indirect effect on potato yield.

(1) Effect of net photosynthetic rate $\left(\mathrm{X}_{9}\right)$ on potato yield

The direct path coefficient between net photosynthetic rate and potato yield was 0.804 . Among the four physiological indices, net photosynthetic rate has the greatest direct impact on potato yield, making it a key physiological factor that affects potato yield. In terms of indirect effect, net photosynthetic rate exerts a positive impact on transpiration rate and intercellular carbon dioxide concentration, and a negative impact on chlorophyll content. However, the indirect effect is not significant, as the indirect path coefficient was 0.072 . Therefore, net photosynthetic rate mainly directly affects potato yield.

(2) Effect of intercellular carbon dioxide concentration $\left(\mathrm{X}_{10}\right)$ on potato yield

The direct path coefficient between intercellular carbon dioxide concentration and potato yield was -0.225 , i.e. this factor has a significant negative effect on potato yield. With an indirect path coefficient of -0.252 , intercellular carbon dioxide concentration exerts a positive impact on transpiration rate, and a negative impact on net photosynthetic rate, and chlorophyll content. Overall, the indirect effect is highly negative. Therefore, intercellular carbon dioxide concentration mainly indirectly affects potato yield.

(3) Effect of chlorophyll content $\left(X_{11}\right)$ on potato yield

The direct path coefficient between chlorophyll content and potato yield was -0.011 , while the total indirect effect of chlorophyll content on potato yield via transpiration rate, net photosynthetic rate, and intercellular carbon dioxide concentration was 0.018 . Hence, chlorophyll content has a slight impact on potato yield, which is mainly manifested through the other physiological reactions.

(4) Effect of transpiration rate $\left(X_{8}\right)$ on potato yield

The direct path coefficient between transpiration rate and potato yield was 0.010 . Meanwhile, the transpiration rate has a positive indirect effect on potato yield via net photosynthetic rate, and a negative indirect effect via intercellular carbon dioxide concentration. The total indirect effect was -0.062 , about 6.2 times of its positive effect. This means transpiration rate mainly suppresses potato yield by affecting the other physiological indices.

(5) Degree of determination

By absolute value, the 11 coefficients of determination can be ranked in descending order as dy. $2>$ dy.e $>$ dy $.23>$ dy $.3>$ dy $.13>$ dy $.12>$ dy $.24>$ dy $.34>$ dy $.4>$ dy. $1>$ dy.14 (dy.1-4 are transpiration rate, net photosynthetic rate, intercellular carbon dioxide concentration, and chlorophyll content, respectively). From the ranking of these coefficients, it is clear that net photosynthetic rate has the greatest effect on potato yield, followed in turn by the mutual effect between environmental error, net photosynthetic rate and intercellular carbon dioxide concentration, intercellular carbon dioxide concentration, transpiration rate and intercellular carbon dioxide concentration, and transpiration rate and net 
photosynthetic rate.

(6) Contributions of physiological indices to the reliability $\mathrm{R}^{2}$ of regression equation

The contributions of independent variables were $P_{y .1} r_{1 y}=$ $0.0005, P_{y .2} r_{2 y}=0.7052, P_{y .3} r_{3 y}=0.1073$, and $P_{y .4} r_{4 y}=-0.0001$. By the contribution to the reliability $\mathrm{R}^{2}$, the physiological indices can be ranked in descending order as net photosynthetic rate $\left(\mathrm{X}_{9}\right)$, intercellular carbon dioxide concentration $\left(\mathrm{X}_{10}\right)$, transpiration rate $\left(\mathrm{X}_{8}\right)$, chlorophyll content $\left(\mathrm{X}_{11}\right)$. Net photosynthetic rate makes a much larger contribution than the other physiological indices.

\section{DISCUSSION}

This paper mainly explores the relationship between agronomic traits, physiological indices and potato yield. The environmental error was considered in the exploration process, because other factors can greatly affect potato yield.

In the study of Potato Intercropping with other crops, Wilkinson et al. [4] found that fresh weight of aboveground part had an important impact on yield per plant, that is, fresh weight per plant had important significance on yield.

Wurr et al., [5] Sharma et al. [6] and Deng et al., [7] The main characters (dry matter content, starch content, reducing sugar content), root length and leaf number of tubers laid the foundation for the study of many important agronomic traits.

The difference may arise from cultivar difference and environmental changes. although leaf area index increases with planting density, potato yield is not positively correlated with leaf area index; for the potato population, there is a suitable range for leaf area index, which leads to the interval of that factor in the multiple regression equation of agronomic traits.

Our research demonstrates that chlorophyll content contributes little to the reliability of the regression equation, and has very limited impact on potato yield [8]. The possible reason is that the strong light of the measurement process causes he photo-oxidation and decomposition of chlorophyll. The resulting error in chlorophyll content leads to data difference. The close correlation between chlorophyll content and photosynthesis ability of the crop: the higher the chlorophyll content, the stronger the photosynthesis ability, and the better the production ability and yield of potatoes. This means chlorophyll content contributes to potato yield by affecting net photosynthetic rate. The key to yield increase lies in the photosynthesis effect. In our tests, the overall photosynthesis effect was discussed in a short term, without considering the photosynthesis potential.

The test data are obtained from the eco-environment of potatoes in mountainous regions of southwestern China. In 2018, Li Peihua from Sichuan Potato Key Laboratory, Xichang University, following the research results, reduced the planting density, increased the stem diameter, and promoted yield per plant, setting a new record of potato yield per unit area in southwestern China: $5,572.5 \mathrm{~kg} / 667 \mathrm{~m}^{2}$. This achievement fully demonstrates the scientific nature of our research. In actual production, the cultivation effect might change in different ecological regions, and the relevant parameters should be adjusted based on local soil conditions and climate.

\section{CONCLUSIONS}

This paper carries out multiple regression analysis, correlation analysis, and path analysis on the 7 agronomic traits and 4 physiological indices that are related to the yield of the cultivar Qingshu 9. The main conclusions are as follows:

(1) Multiple regression analysis shows that potato yield is mainly affected by three agronomic traits, namely, stem diameter, yield per plant, and leaf area index, and two physiological indices, namely, net photosynthetic rate, and intercellular carbon dioxide concentration. To improve potato yield, special attention should be paid to improving the plant profile, that is, reducing stem diameter, such as to properly increase yield per plant [9].

For the population of potatoes, the leaf area index must be controlled, for this index is mainly affected by number of main stems and yield per plant. The influence is manifested as the coordination between the density of aboveground parts and underground tubers (there is little report on the number of leaves or branches). That is, the stem diameter should be cut down through reasonable control of plant height and reduction of stem diameter in the early phase of flowering.

In terms of fertilization, the $\mathrm{P}$ and $\mathrm{K}$ fertilizers must be coordinated to strike a balance between yield per plant and number of tubers per plant, thus increasing the leaf area index. Under a suitable plant density, the potato yield could be increased by lowering the intercellular carbon dioxide concentration.

(2) Correlation analysis shows that, among main agronomic traits, potato yield is significantly correlated with plant height, stem diameter, yield per plant, and emergence rate. Based on correlation degree, these traits can be ranked as yield per plant $>$ plant height $>$ stem diameter $>$ emergence rate $>$ number of tubers per plant $>$ leaf area index $>$ number of main stems.

Among these traits, plant height and stem diameter work together to suppress potato yield. If plant height is too large, it will negatively affect single plant weight and number of tubers per plant, and eventually lower potato yield. Yield per plant has a significant correlation with number of tubers per plant, indicating that a high yield per plant mainly comes from the growing number of tubers per plant and partly from other factors.

The correlation between LAI [10] and potato yield was weak. The relationship between LAI and other traits did not reflect the significant positive effect of Lai on tuber yield.

Physiologically, potato yield is significantly correlated with net photosynthetic rate and intercellular carbon dioxide concentration. Based on the correlation degree, the physiological indices can be ranked as net photosynthetic rate $>$ intercellular carbon dioxide concentration $>$ transpiration rate $>$ chlorophyll content. Among them, transpiration rate has a significant positive correlation with intercellular carbon dioxide concentration. Both factors have a negative impact on potato yield. Under a suitable planting density, the transpiration rate is compatible with intercellular carbon dioxide concentration.

As the density increases, the net photosynthetic rate drops at a growing rate. With the growth in photosynthetic intensity, if the planting density is too high, the field permeability will decrease [11]. In this case, if the plant is too tall, lots of invalid leaves will engage in photorespiration. This pushes up intercellular carbon dioxide concentration and generates a large amount of water. Then, the stomas will open, and the transpiration will pick up speed. As a result, transpiration rate 
will rise together with intercellular carbon dioxide concentration, slowing down the tuber yield. The internal change may be that most of the main carbohydrates are used by aboveground part [12]. This echoes with the phenomena that potatoes grow excessively and suffer from lodging, when the plant density is high.

(3) The results of path analysis match with the conclusions of the relevant research. Based on the direct effect on potato yield, the agronomic traits can be ranked as yield per plant $>$ leaf area index $>$ stem diameter $>$ plant height $>$ emergence rate $>$ number of tubers per plant $>$ number of main stems; the physiological indices can be ranked as net photosynthetic rate $>$ intercellular carbon dioxide concentration $>$ transpiration rate $>$ chlorophyll content.

Based on the direct contribution to potato yield, the agronomic traits can be ranked as yield per plant $>$ stem diameter $>$ plant height $>$ leaf area index $>$ emergence rate $>$ number of tubers per plant $>$ number of main stems; the physiological indices can be ranked as net photosynthetic rate $>$ intercellular carbon dioxide concentration $>$ transpiration rate $>$ chlorophyll content.

In terms of agronomic traits, plant height, stem diameter, and leaf area index make relatively high contributions to potato yield, indicating that the growth of aboveground part has a greater impact on the total potato yield than that of the underground part. The contribution of number of main stems is extremely low. This means the luxuriance of potato plants mainly affects leaf area index through the changing plant density, plant height, and stem diameter.

In terms of physiological indices, net photosynthetic rate is the most important index that affects potato yield. Therefore, the growth of potato yield is essentially the accumulation of synthetic organic matter $[11,12]$. The direct effects of physiological indices on potato yield match their contributions to the latter. Hence, the physiological indices have a single but obviously changing effect on the potato yield. To regulation potato yield, it is necessary to closely monitor the field changes of physiological indices.

(4) To sum up, the key to improving potato yield is to control the growth of aboveground part and regulate the leaf area and photosynthetic effect of potato population.

For instance, the potato yield could be increased by lowering plant height and stem diameter.

Under the low density of 52500 plants / hm2, the plant height of potato increased the least after the final flowering stage, which indicated that plant height could be reduced by adjusting planting density.

The effect of planting density on the yield of Qingshu 9 in high altitude area of Sichuan Province showed that when the planting density was controlled in the range of 52500-75000 dibbles / hm2, the tuber weight per plant, commercial potato rate and fresh potato yield were decreased. Therefore, the plant height can be reduced by lowering planting density, which in turn increases yield per plant, and then the potato yield.

Under a certain $\mathrm{N}$ level, the $\mathrm{P}$ level has a positive effect on net photosynthetic rate, while a low $\mathrm{K}$ level has a negative effect on net photosynthetic rate. Rational application of nitrogen fertilizer can improve the net photosynthetic rate of potato functional leaves $[13,14]$. These findings demonstrate the significant effects of $\mathrm{N}, \mathrm{P}$ and $\mathrm{K}$ on photosynthesis. To bolster potato yield, it is critical to coordinate agronomic traits and physiological indies, and clarify the effects of planting density, $\mathrm{N}, \mathrm{P}$, and $\mathrm{K}$ on potato yield.
Based on our results, the future research will further study the relationship between physiological indices and plant profile, develop high-yield, high-quality cultivation model, and systematically adjust agronomic measures as per environmental traits and physiological states of potatoes [15].

\section{ACKNOWLEDGMENT}

Sichuan Science and Technology Plan project "Panxi area potato seed potato breeding key technology integration research and demonstration" (2016NZ0056); Sichuan Province "Thirteenth Five-Year" potato breeding research project "Panxi area potato staple new variety selection and promotion "(2016NYZ0032-4); "Sichuan Potato Innovation Team of National Modern Agricultural Industry Technology System" (Sichuan Finance Technology [2019] No. 59); Research on the Agricultural Meteorological Index System of Food Crops in Sichuan Province (2018-Key-05-01); Talent Research Fund Project of West China Normal University (17YC364).

\section{REFERENCES}

[1] Rong, G., Ning, Y., Cao, X., Su, Y., Li, J., Li, L., Liu, L., Zhou, D. (2018). Evaluation of optimal straw incorporation characteristics based on quadratic orthogonal rotation combination design. The Journal of Agricultural Science, 156(3): 367-377. https://doi.org/10.1017/S002185961800028X

[2] Hou, X., Li, R., He, W., Dai, X., Ma, K., Liang, Y. (2018) Superabsorbent polymers influence soil physical properties and increase potato tuber yield in a dryfarming region. Journal of Soils and Sediments, 18(3): 816-826. https://doi.org/10.1007/s11368-017-1818-x

[3] Liu, W., Zhang, J., Yang, J., Liu, P., Dong, S., Li, D., Sun, Q. (2011). Effect of plant density on grain yield dry matter accumulation and partitioning in summer maize cultivar Denghai 661. Acta Agronomica Sinica, 37(7): 1301-1307.

[4] Wilkinson, S., Weston, A.K., Marks, D.J. (2019). Stabilising Urea amine nitrogen increases potato tuber yield by increasing chlorophyll content, reducing shoot growth rate and increasing biomass partitioning to roots and tubers. Potato Research, 63: 217-239. https://doi.org/10.1007/s11540-019-09436-x

[5] Wurr, D.C.E., Hole, C.C., Fellows, J.R., Milling, J., Lynn, J.R., O'brien, P.J. (1997). The effect of some environmental factors on potato tuber numbers. Potato Research, 40(3): 297-306. https://doi.org/10.1007/BF02358011

[6] Sharma, V., Kaushik, S. K., Singh, B., Raigond, P. (2016). Variation in biochemical parameters in different parts of potato tubers for processing purposes. Journal of Food Science and Technology, 53(4): 2040-2046. https://doi.org/10.1007/s13197-016-2173-4

[7] Deng, F., Wang, L., Liu, L., Liu, D., Ren, W., Yang, W. (2012). Effects of cultivation methods on dry matter production and yield of rice under different ecological conditions. Acta Agronomica Sinica, 38(10): 1930-1942.

[8] Pieristè, M., Neimane, S., Solanki, T., Nybakken, L., Jones, A.G., Forey, E., Robson, T.M. (2020). Ultraviolet radiation accelerates photodegradation under controlled 
conditions but slows the decomposition of senescent leaves from forest stands in southern Finland. Plant Physiology and Biochemistry, 146: 42-54. https://doi.org/10.1016/j.plaphy.2019.11.005

[9] Zheng, S.L., Wang, L.J., Wan, N.X., Zhong, L., Zhou, S.M., He, W., Yuan, J.C. (2016). Response of potato tuber number and spatial distribution to plant density in different growing seasons in Southwest China. Frontiers in Plant Science, 7: 365. https://doi.org/10.3389/fpls.2016.00365

[10] Huang, J., Sedano, F., Huang, Y., Ma, H., Li, X., Liang, S., Wu, W. (2016). Assimilating a synthetic Kalman filter leaf area index series into the WOFOST model to improve regional winter wheat yield estimation. Agricultural and Forest Meteorology, 216: 188-202. https://doi.org/10.1016/j.agrformet.2015.10.013

[11] Chatzistathis, T., Papadakis, I.E., Papaioannou, A., Chatzissavvidis, C., Giannakoula, A. (2020). Comparative study effects between manure application and a controlled-release fertilizer on the growth, nutrient uptake, photosystem II activity and photosynthetic rate of Olea europaea L. (cv.'Koroneiki'). Scientia Horticulturae 264 https://doi.org/10.1016/j.scienta.2020.109176
[12] Li, Y., Li, H., Li, Y., Zhang, S. (2017). Improving wateruse efficiency by decreasing stomatal conductance and transpiration rate to maintain higher ear photosynthetic rate in drought-resistant wheat. The Crop Journal, 5(3): 231-239. https://doi.org/10.1016/j.cj.2017.01.001

[13] Ren, S.M., Deng, Y.C., Wen, F.J., Hussain, S., Pu, Q.M., Yu, X.B., Liu, W.G., Yang, W.Y. (2018). Effects of intercropping on the transformation of carbohydrate related substances in stem of soybean seedling stage and its relationship with leaf photosynthesis. entia Agricultura Sinica, 2018(7): 1272-1282.

[14] Liu, C., Liu, F., Ravnskov, S., Rubæk, G.H., Sun, Z., Andersen, M.N. (2017). Impact of wood biochar and its interactions with mycorrhizal fungi, phosphorus fertilization and irrigation strategies on potato growth. Journal of Agronomy and Crop Science, 203(2): 131-145. https://doi.org/10.1111/jac.12185

[15] Zhang, Y.L., Wang, F.X., Shock, C.C., Yang, K.J., Kang, S.Z., Qin, J.T., Li, S.E. (2017). Influence of different plastic film mulches and wetted soil percentages on potato grown under drip irrigation. Agricultural Water Management, 180 : 160-171. 